\title{
Knickpoint Finder: ferramenta para a busca de geossítios de relevante interesse para o geoturismo
}

\author{
Knickpoint Finder: tool for searching geosites of relevant interest for geotourism \\ EDUARDO SALAMUNI, EDENILSON ROBERTO DO NASCIMENTO, PEDRO AUGUSTO HAUCK DA SILVA, \\ GUSTAVO LOPES QUEIROZ, GRACIANY DA SILVA \\ Universidade Federal do Paraná - salamuni@ufpr.br
}

\begin{abstract}
Resumo
O trabalho objetiva mostrar a aplicação no geoturismo de uma nova ferramenta computacional de análise morfométrica da rede de drenagem baseada nos métodos de Hack $(1957,1973)$ e Etchebehere $(2004)$, para aplicação em estudos de enfoque neotectônico. A rotina criada trabalha a partir de um modelo digital de elevação (MDE) de modo a gerar um mapa de pontos de ruptura de declive de drenagem e/ou quebra de relevo (knickpoints) e foi programada em Python para uso acoplado ao software de sistemas de informação geográfica $\operatorname{ArcGIS}^{\circledR}$, denominada de Knickpoint Finder.Uma área de estudo foi selecionada de maneira a testar e avaliar a capacidade do software na análise e identificação de knickpoints a partir do estudo da morfologia de um recorte geográfico na Serra do Mar no estado do Paraná, com o objetivo de determinar possíveis geossítios com interesse geoturístico. Após a aplicação da ferramenta na área de estudo constatou-se que os dados de knickpoints obtidos podem caracterizar com rapidez e eficácia pontos de interesse relevante à pesquisa geoturística inicial, principalmente no que tange ao inventário de pontos de beleza cênica relevante em se tratando de corredeiras, cachoeiras ou cascatas. Para que a análise regional possa ser realizada a contento é necessário o emprego de técnicas de representação espacial de dados que podem ser realizadas pelo próprio $\operatorname{ArcGIS}^{\circledR}$, imediatamente após o processamento do Knickpoint Finder. Os resultados da técnica mostraram-se satisfatórios na correlação da maior ocorrência de knickpoints com a probabilidade do encontro de geossítios em áreas de grande amplitude, constatando-se ganho de velocidade de delimitação dos mesmos. Desta forma pode-se considerar a ferramenta virtual obtida como satisfatório recurso de auxílio na análise morfométrica voltada ao geoturismo, podendo ser aplicada em qualquer área onde haja cobertura de modelos digitais de elevação.
\end{abstract}

Palavras-chave: Geoturismo; geossítios; MDE; knickpoint; software.

\begin{abstract}
The study aims to illustrate the geotourism application of a new computational tool for morphometric analysis of the drainage network that is based on Hack $(1957,1973)$ and Etchebehere $(2004)$, for application in studies of neotectonic approach. The computational routine works starting from a digital elevation model (DEM) to generate a map of drainage-slope breaking points and/or relief break (knickpoints) and was programmed in Python for use coupled to the geographical information systems software ArcGIS ${ }^{\circledR}$, and has been named Knickpoint Finder. An area of study was selected in order to test and evaluate the software's ability to analyze and identify knickpoints from the study of the morphology of a geographical cutout in the Serra do Mar in the state of Paraná, in order to determine possible geosites with geotouristic interest. After application of the tool in the area of study, it was verified that the knickpoint data obtained can characterize quickly and effectively points of interest relevant to the initial geotouristic research, especially in regard to the inventory of relevant points of scenic beauty when it comes to rapids, waterfalls or cascades. To ensure that the regional analysis can be done successfully it is necessary to employ spatial data representation techniques which can be performed directly in ArcGIS, immediately after the processing of Knickpoint Finder. The results of the technique where satisfactory in the correlation of the highest occurrence of knickpoints with the probability of finding geosites in extensive areas, which demonstrated the speed gain in delimiting these sites. Thus, the obtained virtual tool is considered a satisfactory feature in assisting morphometric analysis focused on geotourism, which can be applied in any area where there is coverage of digital elevation models.
\end{abstract}

Key words: Geotourism; geosites; DEM; knickpoint; software.

\section{INTRODUÇÃO}

De acordo com Hose (1995), o turista que visita um patrimônio natural, ao adquirir conhecimento a respeito da geologia e/ou geomorfologia de um sítio, deixa de ser apenas um espectador da estética da paisagem. Assim, o geoturismo passa a ter também por missão agregar conhecimento técnico e/ou científico ao valor estético, que sendo subjetivo, pode valorizar ainda mais a paisagem, inclusive para que estas sejam preservadas como patrimônios naturais ou culturais.

Segundo Moreira (2011) o geoturismo é uma tendência mundial que vem propiciando uma atividade educativa, além de acrescentar "uma nova dimensão e diversidade ao produto turístico oferecido". Liccardo et al. (2008) ressaltam que o geoturismo fundamenta-se nos conceitos de geodiversidade, patrimônio geológico e 
geoconservação. Assim sendo, sítios geológicos (ou geossítios) são locais de relevante interesse para o estudo geológico ou geomorfológico, importante sob o ponto de vista geocientífico, que necessitam possuir apelo didático e/ou turístico, fundamentalmente devido à singularidade das formações geológicas tais como afloramentos especiais, artefatos naturais, por exemplo, uma cratera de impacto de meteorito ou o próprio meteorito, grandes bombas vulcânicas - camadas ou formações fossilíferas, ou sítios geomorfológicos marcantes pela sua beleza estética natural e/ou pela sua história evolutiva, fazem parte do universo da geodiversidade que pode servir aos propósitos do geoturismo. Grandes exposições artificiais tais como pedreiras, apesar de sua ausência de apelo cênico natural, podem ser úteis aos estudos da geodiversidade local.

A determinação de elementos geomorfológicos ou morfoestruturais notáveis, que constituem um dos tipos de geossítios, a partir de imagens de abrangência regional, traz uma complexidade inerente devido à dificuldade de se realizar a análise visual ponto a ponto. Em razão dessas limitações, foi confeccionada uma rotina automática, ou seja, um software que funciona de maneira acoplada ao $\operatorname{ArcGIS}^{\circledR}$, denominado de Knickpoint Finder, cuja finalidade é a de buscar locais onde há quebras de relevo em segmentos de drenagens, perenes ou intermitentes, denominados de knickpoints.

Segundo Crosby \& Whipple (2006) knickpoints são quebras ou rupturas de declive, que criam anomalias de relevo no perfil longitudinal do canal de um rio. De acordo com esses autores e outros pesquisadores, tais como Gardner (1983), Whipple (2004), Bishop et al. (2005) e Harbor et al. (2005), são várias as causas desse desequilíbrio mas as principais estão ligadas à natureza dos litotipos envolvidos, sua erosão diferencial e a brusca mudança de nível de base, inclusive pelas estruturas tectônicas herdadas de ciclos anteriores ou ainda pela neotectônica local.

Geralmente, os knickpoints são anomalias, geradas a partir da ampliação do gradiente topográfico, que formam corredeiras e cachoeiras. Portanto, a determinação de knickpoints é um dos caminhos para se identificar cachoeiras que podem ser consideradas como bons geossítios, posto que, quase sempre, estão associados à formação e modificação da paisagem a ser considerada como atrativa ao geoturismo.

O objetivo do presente trabalho é explanar genericamente o funcionamento do software Knickpoint Finder, bem como abordar sua aplicabilidade no geoturismo por meio da apresentação de um estudo de caso, ou seja, o Salto Morato localizado na Serra do Mar paranaense e classificado como geossítio relevante, ligado a uma quebra de relevo, que por sua vez configura uma anomalia de drenagem.

\section{MÉTODO}

O trabalho basicamente foi desenvolvido a partir de testes laboratoriais por meio de geoprocessamento e observação de resultados em imagens orbitais, as quais foram comparadas com fotografias reais de geoformas notáveis.

Como necessárias para o desenvolvimento do trabalho foram utilizadas as seguintes ferramentas: o software Knickpoint Finder para a busca de anomalias de relevo em drenagem; o algoritmo denominado de River Merge desenvolvido para unificar segmentos de drenagem; o software de geoprocessamento ArcGIS v.10.1 ${ }^{\circledR}$ para o sistema básico de integração de informação e plataforma de funcionamento do Knickpoint Finder; as imagens raster do Shuttle Radar Topography Mission (SRTM ${ }^{\circledR}$ - NASA), processadas - via interpolação pelo método de convolução cúbica - pelo Projeto Topodata e com resolução espacial de $30 \mathrm{~m}$. Para a busca dos knickpoints identificados foram visualizadas as imagens do Google Earth ${ }^{\circledR}$, onde foram localizadas as referências espaciais dos pontos de interesse turístico.

Os equipamentos de informática utilizados são computadores simples de mesa, com capacidade de processamento mediana a boa, e funcionamento de dois monitores simultâneos. A plataforma na qual foi desenvolvido o software é o Windows ${ }^{\circledR}$, todavia o algoritmo pode ser adaptado para programas de GIS desenvolvidos para o Linux, porém isso depende do trabalho de adaptação de um usuário mais especializado.

\section{DESENVOLVIMENTO}

\subsection{RELAÇÕES GEOMÓRFICAS E GEOTURÍSTICAS}

Em qualquer região é possível encontrar locais com características do meio físico que, pela sua natureza, possam ser consideradas como patrimônio geológico. Em geral são paisagens que apresentam uma rica geodiversidade, seja pela sua formação original seja pela transformação da mesma, via intemperização, nesse caso o conjunto Pão de Açúcar e Corcovado; ou deformação estrutural, nesse caso a impressionante Zona de Falha Além Paraíba. Ambos os casos, localizados no estado do Rio de Janeiro, podem ser denominados de geossítio sem qualquer restrição.

Tais geossítios são passíveis de receber a visita de turistas, leigos ou profissionais das geociências, cujo olhar diferenciado, proporcionado pelo conhecimento geológico e morfoestrutural já levantado, pode impactar positivamente a atividade geoturística. Tal disseminação do conhecimento comprovadamente valoriza o ambiente do entorno como um todo, já que inibe sua degradação por meio de impactos antrópicos negativos e, consequentemente, tem o viés de contribuir para o desenvolvimento econômico local, por meio da atividade 
turística sustentável.

De acordo com Rodrigues (2009), o Patrimônio Geológico não pode ser visto exclusivamente do ponto de vista do conhecimento científico mas além disso, deve ter condições de ser transmitido ao público por meio de ações de divulgação de Geologia que se encaixam na própria perspectiva geoturística, que se desenvolve em torno de um geossítio ou geotopo. Os geossítios podem ser pontos ou áreas naturais de notável beleza cênica e que possuem formações de interesse geocientífico, tanto no que concerne à sua formação ou à sua esculturação. Em geral ali se confunde a natureza geológica do substrato ou do elemento cênico com sua evolução geológico intrínsecas da região em foco, bem como sua evolução geomorfológica, essencialmente ligada a processos morfotectônicas, (Nascimento et al. 2008, Silva 2008).

Nesse contexto, a quebra de relevo, como elemento geomórfico, é um tipo de modificação na paisagem, indicativas de relevantes estruturas (morfoestruturas) que possibilitam a predição ou a definição de eventuais geossítios, passíveis de preservação e/ou uso para o geoturismo (Piekarz 2011), ou seja, são intrinsicamente relevantes como Patrimônio Geológico.

A determinação de uma área ou local (geoforma) como geossítio ou geotopo, de maneira geral, independe da sua escala de abrangência, posto que a grandeza escalar não determina, a princípio, sua importância geocientífica. Igualmente, um geossítio independe de sua importância do ponto de vista econômico.Tanto no primeiro quanto no segundo caso deve-se considerar que tanto as Cataratas do Iguaçu quanto o Salto Santa Rosa na região central dos Campos Gerais (Tibagi-PR) devem ser reconhecidos como importantes sítios geológicos/geomorfológicos. No entanto, é necessário considerar que o geoturismo como atividade, depende, em parte, de uma vertente econômica.

O conhecimento atual das geoformas que podem ser caracterizadas como importantes geossítios ainda é baixo no Paraná (Lima et al. 2010), posto que a preocupação em catalogar tais elementos naturais é bastante recente, como mostram documentos técnicos internos da Minerais do Paraná S.A. (MINEROPAR). A dificuldade está centrada na complexidade da localização e da avaliação in situ de um dado elemento geomórfico, necessária à sua consideração como geossítio relevante, tanto do ponto de vista de sua beleza cênica quanto do interesse geológico-científico que desperta em estudiosos e/ou visitantes.

Em função disso é interessante considerar que a utilização de ferramentas automáticas e/ou digitais de visualização em forma de imagens de satélite, modelos digitais de elevação, mapas hipsométricos, fotografias aéreas, entre outros pode ampliar, em muito, o inventário de geossítios. Os softwares de visualização automáticos estão disponíveis em vários ambientes, desde os mais sofisticados de GIS até os populares Google Earth ${ }^{\circledR}$ e BingMaps ${ }^{\circledR}$. Todavia, esquadrinhar uma imagem em busca de um desconhecido elemento geomórfico de real interesse ao geoturismo é um trabalho manual bastante cansativo e, na maior parte das vezes, pouco eficaz.

O software Knickpoint Finder, acoplado ao ArcGIS, busca pontos que caracterizariam rupturas no terreno, que recebem o nome técnico de knickpoints, e que em síntese, estando localizados em um rio podem revelar a existência de uma cascata ou cachoeira e eventualmente poderiam ser considerados geossítios ou geotopos. A busca se realiza de forma automática, a partir de imagens que possuam dados altimétricos, independente da escala de levantamento e abrangência regional e diminui em muito e até anula a complexidade inerente à identificação manual de locais onde há tais rupturas de relevo. Em geral, tais anomalias não são facilmente identificáveis em imagens de satélite ou fotografias aéreas, pois o caráter bidimensional comum à maioria das imagens impede a identificação e mensuração dos knickpoints. Sendo assim, é necessária a utilização de imagens com dados topográficos para caracterizar cachoeiras, cascatas, corredeiras, enfim locais com mudanças abruptas de relevo, a partir de um perfil longitudinal, ou um trecho do perfil de um rio ou do curso de uma drenagem intermitente.

É importante ressaltar que os estudos de deformação de superfície ou de paisagens mostram que rios ou canais de drenagem naturais são bastante sensíveis às modificações da cota do terreno, ou níveis geodésicos de referência, ainda mais quando ocorrem com rapidez em resposta a sistemas tectônicos ativos (Keller\& Pinter 1996). Tal consideração tem sido abordada por diversos autores que estudam processos de mudanças morfológicas do terreno em áreas sujeitas a sismos a partir de processos tectônicos ativos (Volkov et al. 1967, Burnett \& Schumm 1983, Rodriguez \& Suguio 1992, Merrits \& Hesterberg 1994).

Ou seja, rios são excelentes elementos geomórficos com possibilidade de mostrar estruturas, ao nível de superfície do terreno, criadas a partir de processos tectônicos (morfotectônica). A quebra de relevo é uma das características mais notáveis na superfície e pode ser caracterizada por importantes anomalias de drenagem (nesse caso traduzidas por cachoeiras ou cascatas) e, em geral, são representados pelos knickpoints, os quais, dependendo da diferença da cota da quebra de relevo, bem como do volume de água e acréscimo de energia propiciam efeitos paisagísticos notáveis. Nesse caso poderiam ser considerados como alvo inicial para considerá-los como geossítios.

O software Knickpoint Finder tem por foco acelerar o processo da análise geomórfica e morfométrica no contexto geomorfológico, possibilitando um bom grau de precisão e detalhe na 
busca desses pontos paisagísticos, que a depender de outros fatores, como por exemplo sua importância geocientífica e sua facilidade de acesso, podem se constituir excelentes pontos geoturísticos.

\subsection{MÉTODOS}

O software Knickpoint Finder se baseia no parâmetro morfométrico proposto por Hack (1973), denominado de índice StreamLenght-Gradient (SL) - ou Índice de Hack - e refere-se a perfis longitudinais de rios ou de segmentos de drenagem, que indicam anomalias locais (Martinez et al. 2011). Esse parâmetroé obtido pelo cálculo da declividade do segmento da drenagem multiplicada pela distância entre o segmento considerado e a nascente do rio. Etchebehere et al. (2004) propuseram uma derivação do Índice de Hack, denominando-o de RDE (Relação Declividade-Extensão), que leva em consideração o aumento da energia da corrente em determinado segmento da drenagem, utilizando como variável a declividade da superfície do canal. $O$ índice RDE para um segmento (RDEs) pode ser calculado da seguinte maneira (figura 1 ):

$$
\operatorname{RDES}=(\Delta \mathrm{H} / \Delta \mathrm{L}) \cdot \mathrm{L} \quad \text { (Eq. 1) }
$$

$\Delta \mathrm{H}=$ diferença altimétrica entre as duas extremidades de um segmento ao longo de um rio;

$\Delta \mathrm{L}=$ extensão do trecho em planta;

$L$ = distância entre a extremidade inferior desse trecho e a nascente do rio.

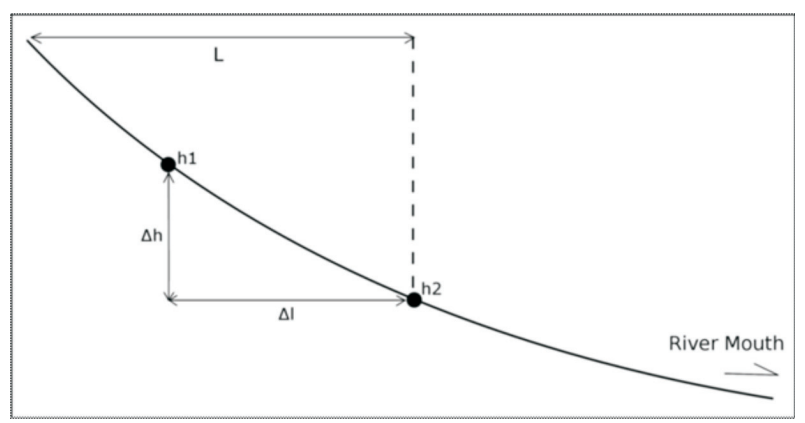

Figura 1 - Perfil longitudinal de um canal, mostrando como o índice RDEs é medido para um segmento de comprimento $\Delta \mathrm{l}$, diferença altimétrica de $\Delta h$, e distância da nascente do rio de $L$.

A variante RDE total (RDEt), que se refere à extensão total de um rio, leva em consideração a declividade total entre a nascente e a foz, e o logaritmo natural de toda a sua extensão (Seeber \& Gornitz 1983, Etchebehere 2006). O cálculo é feito da seguinte forma:

$$
\operatorname{RDEt}=(\Delta \mathrm{H} / \Delta \mathrm{L}) \cdot \ln (\mathrm{L})
$$

O objetivo final, após medir os índices RDEs de diversos segmentos e os índices RDEt de suas respectivas drenagens, é compará-los para determinar quais segmentos possuem declividade anômala.

As anomalias mais significativas determinam os knickpoints de interesse de estudos morfotectônicos ou morfoestruturais. Keller \& Pinter (1996) estudaram o índice SL da San Gabriel Mountains, Sul da Califórnia, e perceberam que ali os valores mostram-se anormalmente altos, o que possibilitou a geração de knickpoints ligados a altas taxas ascensionais de terreno.

$\mathrm{O}$ índice RDE, proposto por Etchebehere et al. (2004), foi utilizado para criar o algoritmo que identifica knickpoints que, por sua vez, embasou a confecção do Knickpoint Finder para operar em conjunto com o software $\mathrm{ArcGIS}^{\circledR}$, como uma toolbox. O algoritmo desta ferramenta utiliza imagens raster com dados altimétricos, de onde a drenagem tridimensional é obtida para a análise de RDEs e RDEt, cujos cálculos necessitam da confecção dos perfis longitudinais completos de todos os rios que estão sendo estudados. Desta forma, é necessário unificar todos os segmentos em cada uma das linhas de drenagem para que seja reconhecida como uma feição única, da cabeceira à foz. Para este processo como não existe ferramenta específica no $\operatorname{ArcGIS}^{\circledR}$, foi criado um algoritmo exclusivo denominado de RiverMerge.

Após a unificação dos segmentos de drenagem, a ferramenta transforma as linhas $2 \mathrm{D}$ da rede de drenagens em linhas 3D, adicionando o valor de altitude (Z), obtido da imagem que contém os dados altimétricos, utilizando-se, no caso do $\operatorname{ArcGIS}^{\circledR}$, da ferramenta InterpolateShape. Após esta etapa cada nó (vértice) de cada linha possuirá os valores de altitude (Z), além de coordenadas X e Y. Ao final do processo é feita a medição dos índices RDE e marcado automaticamente um ponto no mapa (knickpoint).

O banco de dados dos pontos gerados guardam, além das coordenadas $\mathrm{X}$ e $\mathrm{Y}$ e do grau de anomalia, os valores de RDEs, RDEt e RDEs/RDEt do segmento. Há uma relação de escala de trabalho, que é uma variável fornecida pelo usuário, ou seja, quanto menor o valor da equidistância altimétrica fornecida pelo usuário, maior será o número de dados (pontos) no resultado final. Assim, o resultado final da ferramenta Knickpoint Finder é uma malha de pontos, cuja densidade dependeda escala de trabalho e do valor escolhido para as curvas de nível virtuais (equidistância altimétrica fornecida pelo usuário).

\section{DESENVOLVIMENTO E DISCUSSÃO}

Para testar a ferramenta desenvolvida, o KnickpointFinder foi aplicado ao recorte geográfico da Serra do Mar paranaense, com o intuito de obter os knickpoints (figuras 3 e 4), os quais foram analisados à luz dos dados geológicos (figura 2). 
Por meio das figuras 3 e 4, é possível observar que há uma grande quantidade de knickpoints no fronte da escarpa da serra, nos segmentos de rios que formam a bacia hidrográfica litorânea. Isso faz sentido exatamente pelo fato de ali haver importante sequência de quebras de relevo, geradas fundamentalmente por rupturas dos terrenos, nesse caso pela ocorrência de falhas geológicas com direção NE-SW, bem como por alinhamentos estruturais como diques de diabásio com direção NW-SE.

Assim, é possível que as rupturas de terreno, geradas pelas reativações de planos de falhas de direção NSW e também estruturas menores de direção NW, nas quais se acomodam trechos de rios, apresentem boadensidade de knickpoints. Todavia, não se pode descartar que há knickpoints gerados por processos erosivos e/ou intempéricos que agem de forma diversa em litotipos variados, devido às diferenças de resistência entre rochas de natureza diversificadas.

A seleção de áreas com prováveis locais que apresentam pontos geomórficos de beleza cênica relevante, representam os alvos preferenciais para a pesquisa facilitando a busca por pontos de real interesse. É possível traçar um paralelo, dessa forma, com os métodos de exploração mineral e a busca por alvos de interesse econômico.

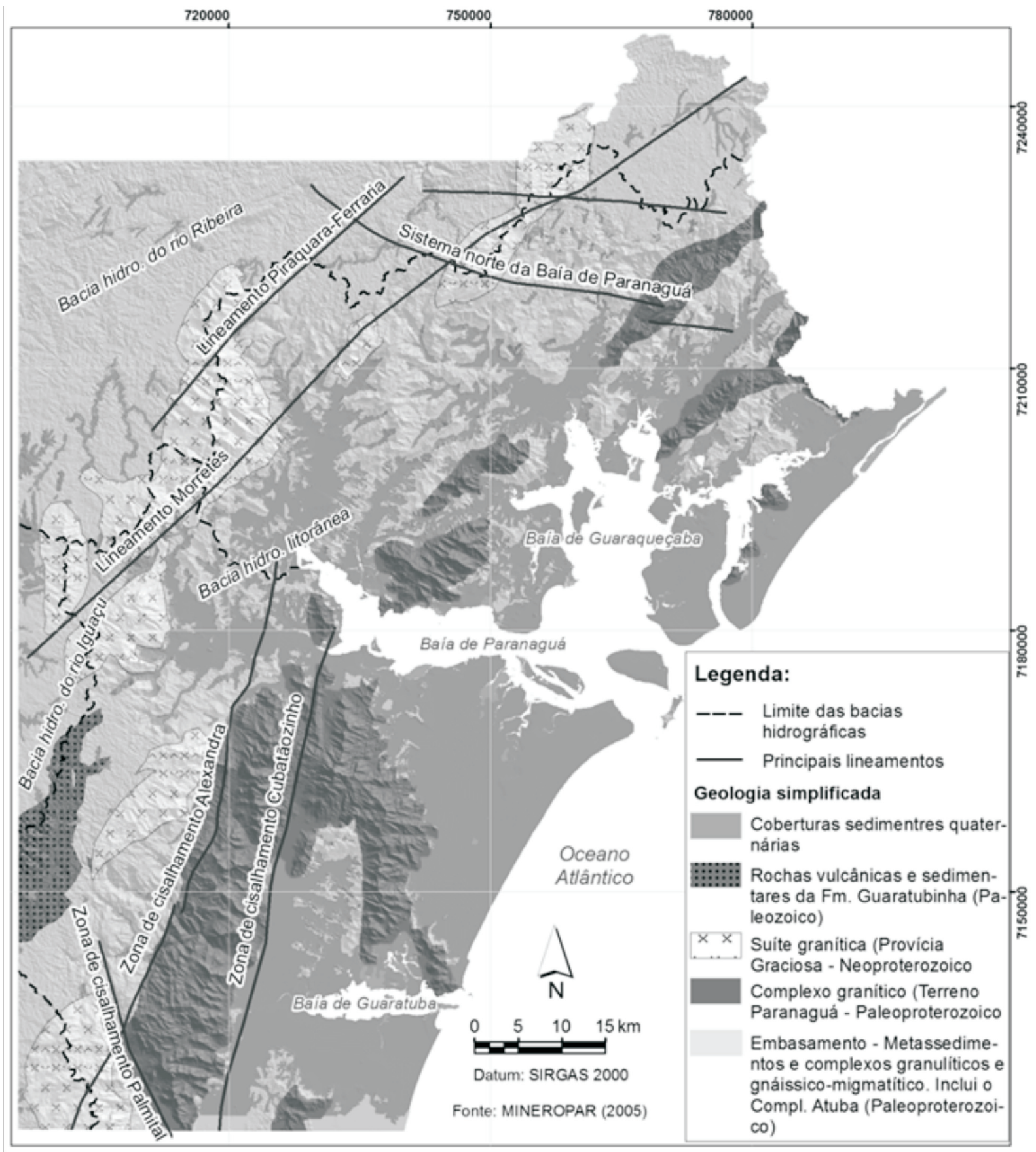

Figura 2 - Mapa geológico simplificado da região da Serra do Mar paranaense (Fonte: Nascimento 2013) 
Partindo-se desse princípio, o método permite que o aumento da escala da imagem aproxime, por sua vez, o objeto de análise e a busca visual restrita a áreas onde o adensamento de knickpoints é maior, permitindo que se possibilite ampliar a identificação dos pontos de interesse. Na figura 4, por exemplo, há três áreas de interesse, a sul, no centro da área e a norte. São nessas áreas que a busca de knickpoints deve se concentrar para que se aumente a chance de encontrar geossítios com potencial vocação geoturística ou até mesmo voltada ao turismo de aventura.

Optando-se por uma dessas concentrações, verifica-se em imagens de satélite do Google Earth o ponto exato onde o Knickpoint, representado por uma cascata/cachoeira, está posicionado. A partir desse ponto é possível determinar se o local encontrado é, de fato, compatível com os critérios intrínsecos a um geossítio.

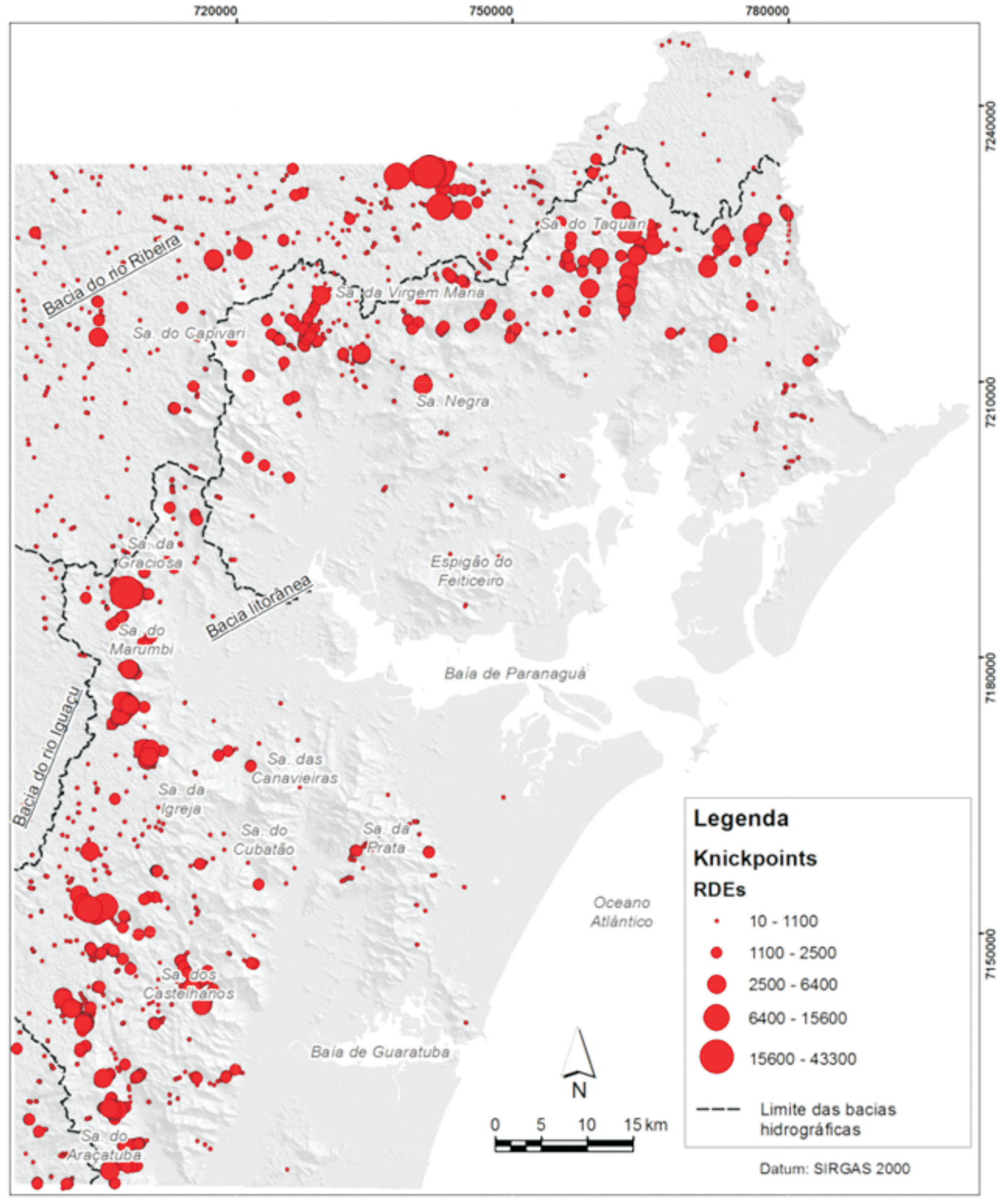

Figura 3-Modelo digital de elevação mostrando os principais knickpoints identificados na área de estudo, a partir dos valores de RDEs. 


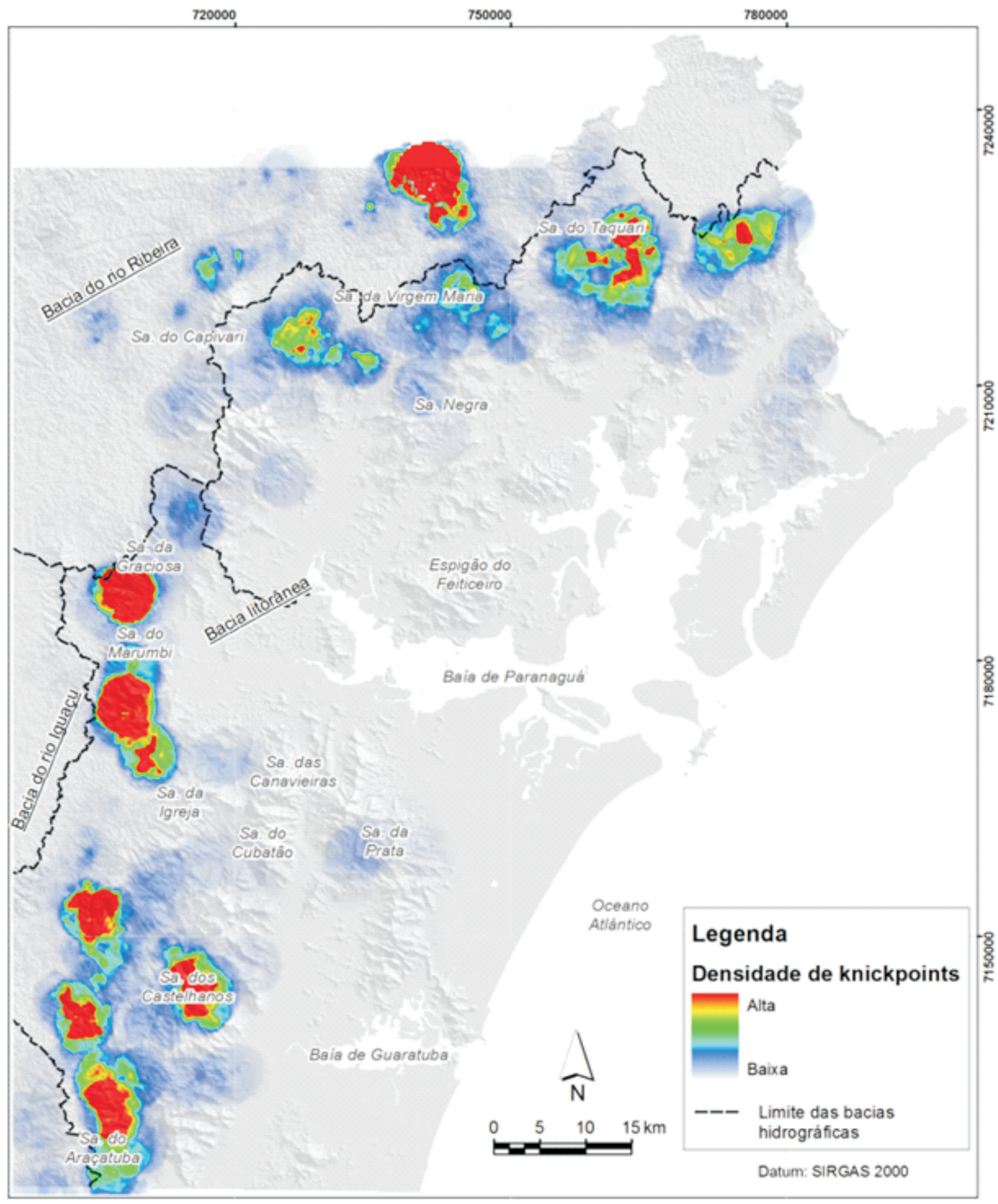

Figura 4-Mapa de estimativa de densidade de knickpoints identificados na área de estudo. 
A figura 5 mostra a sequência utilizada para a busca de um sítio relevante para o desenvolvimento geoturísitico local. Nesse caso o geossítio é representado pela cachoeira de Salto Morato de cerca de $160 \mathrm{~m}$ de queda de água, já conhecida, cujas coordenadas geográficas de latitude é $25^{\circ} 09^{\prime} 50^{\prime \prime}$ S e de longitude é $48^{\circ} 17^{\prime} 54^{\prime \prime} O$.

A figura 6 mostra que foi possível encontrar o Salto Morato e muitos outros pontos de grande beleza natural utilizando-se da técnica de busca simples a partir de imagens de satélite e dos pontos de knickpoints mais marcantes encontrados pelo software.

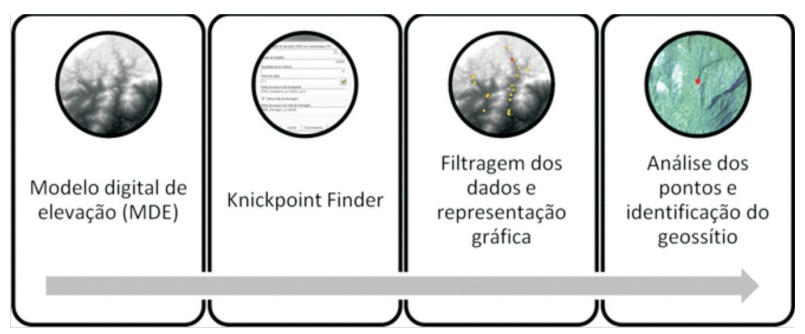

Figura 5 - Sequência de etapas necessárias para se identificar um geossítio a partir de um modelo digital de elevação utilizando-se o software Knickpoint Finder.

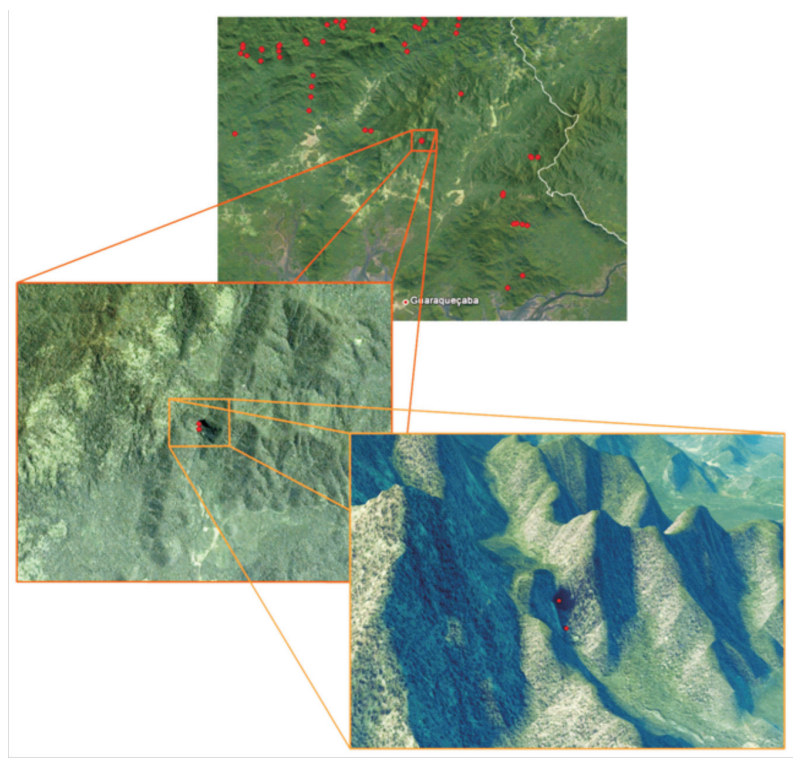

Figura 6 - Esquema de identificação de um ponto geoturístico, neste caso o Salto Morato, a partir de análise multi-escala de imagens de satélite do Google Earth ${ }^{\circledR}$. O relevo apresenta exagero vertical de 3 vezes (escalas indefinidas)
Para a definição de que esse ponto, de fato, constituiria um geossítio seria necessário o levantamento de sua relevância geocientífica, por exemplo ressaltando que nesse caso, caracterizaria a evolução morfotecônica de sua região de abrangência. No caso em tela, o ponto encontrado constitui um excelente referencial para o entendimento da evolução geomorfológica e geológica-estrutural do fronte da escarpa da Serra do Mar. Como já se conhece, de antemão, sua vocação turística, principalmente o turismo de aventura, é possível classificá-lo como um geossítio.

\section{CONCLUSÃO}

O software Knickpoint Finder funciona acoplado ao $\operatorname{ArcGIS}^{\circledR}$. Um dos ganhos fundamentais no processo automático de identificação de knickpoints é a rapidez da busca desse tipo de anomalia, ou elemento morfométrico, em imagens que deve necessariamente estar em formato raster e possuir dados altimétricos.

$\mathrm{O}$ aumento na velocidade e na facilidade de busca de dados morfométricos, no caso os knickpoints, torna a ferramenta eficaz e eficiente na identificação de prováveis geossítios de interesse geoturístico, em se tratando de rupturas de relevo em perfis longitudinais de rios ou segmentos de drenagem.

Os knickpoints necessariamente precisam passar por uma avaliação visual em ferramentas virtuais do tipo Google Earth ${ }^{\circledR}$ e Bing ${ }^{\circledR}$ e para que possam ser considerados geossítios de interesse geoturístico precisam, posteriormente, passar por uma caracterização e avaliação focadas nessa meta. Tal avaliação deve incluir os critérios que têm sido propostos e apresentados em vários trabalhos de pesquisa sobre geoturismo como, por exemplo, a síntese mostrada por Nascimento et al. (2008).

O Knickpoint Finder é um software de código aberto à comunidade e está disponível na forma de arquivo digital no sítio eletrônico do Grupo de Pesquisa em Neotectônica da Universidade Federal do Paraná (http://www.neotectonica.ufpr.br). A partir do código aberto, eventuais interessados podem adaptá-lo em outros programas ou pacote voltados a GIS, necessitando para isso que o algoritmo seja modificado de acordo com as especificações do programa de geoprocessamento.

\section{Referencias}

BISHOP, P.; HOEY, T.B.; JANSEN, J.D.; ARTZA, I.L. 2005 Knickpoint recession rate and catchment area: the case of uplifted rivers in Eastern Scotland. Earth Surface Process \& Landform, 30:767-778.

BURNETT, A.W.; SCHUMM, S.A. 1983 Alluvial river response to neotectonic deformation in Louisiana and Mississippi. Science, v.222, p.49-50.

CROSBY, T.B.; WHIPPLE, K.X. 2006 Knickpoint initiation and distribution within fluvial networks: 236 waterfalls in the Waipaoa River, North Island, New Zealand. Geomorphology, 82:16-38.

ETCHEBEHERE, M.L.C.; SAAD, A.R.; FULFARO, V.J.; PERINOTTO, J.A.J. 2004 Aplicação do Índice "Relação Declividade- Extensão - RDE" na Bacia do Rio do Peixe (SP) para detecção de deformações neotectônicas. Revista do Instituto de Geociências USPSérie Científica, São Paulo, v.4, n.2, p. 43-56, out. 
ETCHEBEHERE, M.L.C.; SAAD, A.R.; SANTONI, G.; CASADO, F.C.; FULFARO, V.J. 2006 Detecção de prováveis deformações neotectônicas no vale do Rio do Peixe, região ocidental paulista, mediante aplicação de índices RDE (Relação DeclividadeExtensão) em segmentos de drenagem. Revista Geociências, UNESP, v.25, n.3, p.271-289.

GARDNER T.W. 1983 Experimental study of knickpoint and longitudinal evolution in cohesive, homogeneous material. Geological Society of America Bulletin, 94:664-672.

HACK, J.T. 1957 Studies of longitudinal stream profiles in Virginia and Maryland. Shorter Contributions to General Geology, 1957. p. 45-97.

HACK, J.T. 1973 Stream-profile analysis and streamgradient index. Journal Research of the U.S. Geol. Survey, v. 1, n. 4, p. 421-429.

HARBOR, D.; BACASTOW, A.; HEATH, A.; ROGERS, J. 2005 Capturing variable knickpoint retreat in the Central Appalachians, USA. Geogr. Fis. Dinam. Quat. 28: 23-36.

HOSE, T.A. 1995 Selling the story of Britain's stone. Environmental Interpretation, 10 (2), 16-17.

KELLER, E.A.; PINTER, N. 1996 Active tectonics, earthquakes, uplift and landscape. Prentice Hall, $338 \mathrm{p}$.

LICCARDO, A.; PIEKARZ, G.; SALAMUNI, E. 2008 Geoturismo em Curitiba. Mineropar, Curitiba-PR, $122 \mathrm{p}$.

LIMA, F.F. DE; BRILHA, J.B.; SALAMUNI, E. 2010 Inventorying geological heritage in large territories: a methodological proposal applied to Brazil. Geoheritage, DOI 10.1007/s12371-010-0014-9

MARTINEZ, M.; HAYAKAWA, E.; STEVAUX, J. C.; PROFETA, J. D. $2011 \mathrm{SL}$ index as indicator of anomalies in the longitudinal profile of the Pirapó River. Revista Geociências, v.30, p.63-76.

MERRITS, D.; HESTERBERG, T. 1994 Stream networks and long-term surface uplift in the New Madrid seismic zone. Sciencem, v. 265, p.1.081-1.084.

MOREIRA, J.C. 2011 Geoturismo e interpretação ambiental. Ed.UEPG, Ponta Grossa-PR, $157 \mathrm{p}$.

NASCIMENTO, E.R. $2013 \quad$ Caracterização morfotectônica e morfoestrutural da Serra do Mar Paranaense. Tese de Doutorado. Departamento de Geologia, UFPR.

NASCIMENTO, M.A.L. DO; RUCHKYS, U.A.; MANTESSONETO, V. 2008 Geodiversidade, geoconservação e geoturismo. SBG-BR, São Paulo-SP, $82 \mathrm{p}$.

PIEKARZ, G. 2011 Geoturismo no Karst. Mineropar, Curitiba-PR, $121 \mathrm{p}$.

RODRIGUES, J.C. 2009 Geoturismo: uma abordagem emergente. In: Neto de Carvalho, C. \&Rodrigues, J.C. (Eds.), Geoturismo e desenvolvimento local. Idanhaa-Nova, 38-60.

RODRIGUEZ, S.K.; SUGUIO, K. 1992 Gradientes hidráulicos das drenagens de $2 \underline{a}$ ordem: uma contribuição para os estudos de neotectônica da "Volta Grande" do rio Xingu, Altamira - PA. In: Congresso Brasileiro de Geologia, 37, 1992, São Paulo. Resumos Expandidos... São Paulo: Sociedade Brasileira de Geologia, p. 598-600.

SEEBER, L.; GORNITZ, V. 1983 River profiles along the Himalayan arc as indicators of active tectonics: Tectonophysics, v.92, p. 335-367.

SILVA, C.R. (ed.) 2008 Geodiversidade do Brasil. CPRM-Serviço Geológico do Brasil. Rio de Janeiro RJ, $263 \mathrm{p}$.

UFPR 2013 Neotectonics research group. Brazil. Available at http://www.neotectonica.ufpr.br/2013/.

VAL, P.F. A., SILVA, C.L. DA; SANTOS, J.M. DOS; MORALES, N.; HARBOR, D. 2013 Distribuição de knickpoints em bacias de drenagem na região de Manaus (AM) e seu potencial para o estudo neotectônico e evolução da paisagem na Amazônia. Simpósio de Geologia da Amazônia.

VOLKOV, N.G.; SOKOLOVSKY, I.L.; SUBBOTIN, A.I. 1967 Effect of recent crustal movements on the shape of longitudinal profiles and water levels in rivers. In: International symposium on river mechanics, Bern (Swiss), 1967. Proceedings.. Bern: International Union of Geodesy and Geophysics, p. 105-116.

WHIPPLE, K.X. 2004 Bedrock rivers and the geomorphology of active orogens. Annual Reviewof Earth andPlanetary Sciences, 32:151-185.
Manuscrito ID 32797

Submetido em julho de 2013

Aceito em setembro de 2013 